\title{
Vertebral Column Resection for the Treatment of Severe Spinal Deformity
}

\author{
Lawrence G. Lenke MD, Brenda A. Sides MA, \\ Linda A. Koester BS, Marsha Hensley RN, \\ Kathy M. Blanke RN
}

Published online: 1 September 2009

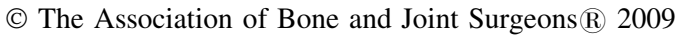

\begin{abstract}
The ability to treat severe pediatric and adult spinal deformities through an all-posterior vertebral column resection (VCR) has obviated the need for a circumferential approach in primary and revision surgery, but there is limited literature evaluating this new approach. Our purpose was therefore to provide further support of this technique. We reviewed 43 patients who underwent a posterior-only VCR using pedicle screws, anteriorly positioned cages, and intraoperative spinal cord monitoring between 2002 and 2006. Diagnoses included severe scoliosis, global kyphosis, angular kyphosis, or kyphoscoliosis. Forty $(93 \%)$ procedures were performed at L1 or cephalad in the spinal cord (SC) territory. Seven patients (18\%) lost intraoperative neurogenic monitoring evoked potentials (NMEPs) data during correction with data returning to baseline after prompt surgical intervention. All patients after surgery were at their baseline or showed improved SC function, whereas no one worsened. Two patients had
\end{abstract}

One or more of the authors receives institutional/research/grant support from Medtronic.

Each author certifies that his or her institution has approved the human protocol for this investigation, all investigations were conducted in conformity with ethical principles of research, and that informed consent for participation in the study was obtained.

Electronic supplementary material The online version of this article (doi:10.1007/s11999-009-1037-x) contains supplementary material, which is available to authorized users.

L. G. Lenke ( $ه)$, B. A. Sides, L. A. Koester, K. M. Blanke Department of Orthopaedic Surgery, Washington University School of Medicine, 660 S Euclid Avenue, Campus Box 8233, St Louis, MO 63110, USA

e-mail: lenkel@wudosis.wustl.edu

M. Hensley

Shriners Hospital for Children, St Louis, MO, USA nerve root palsies postoperatively, which resolved spontaneously at 6 months and 2 weeks. Spinal cord monitoring (specifically NMEP) is mandatory to prevent neurologic complications. Although technically challenging, a singlestage approach offers dramatic correction in both primary and revision surgery of severe spinal deformities.

Level of Evidence: Level IV, therapeutic study. See Guidelines for Authors for a complete description of levels of evidence.

\section{Introduction}

The surgical treatment of severe spinal deformity in the past few decades has been based on a circumferential approach to the spinal column $[6,8,12]$. In a first-stage anterior approach, multilevel discectomies and/or corpectomies are performed for release of the rigid spinal column. In addition, anterior spinal fusion is obtained through grafting of the released disc spaces and/or placement of morselized vertebral body bone back into any corpectomy defects that were performed in anticipation of a circumferential vertebrectomy procedure. Then, during the same anesthetic or on a staged basis, a posterior procedure is performed for instrumentation, correction, and ultimate fusion. Concomitant with the posterior approach, posterior releases of the ligaments and facet joints (Ponté or Smith-Petersen-type osteotomies) are performed versus a posterior laminectomy and pediculectomy for completion of a circumferential vertebral column resection (VCR) approach [4]. This approach has been the standard of care of severe, rigid spinal deformities for several decades once segmental spinal instrumentation made stable instrumentation constructs possible for the treatment of these severe deformities. 
Performing a circumferential VCR for a severe, rigid spinal deformity in modern times was first described by Bradford in the late 1980s [2]. In 1997, he and O. BoachieAdjei further expanded on Bradford's original case series by reporting 16 additional patients undergoing a circumferential VCR [1]. More recently, Suk and colleagues reported a posterior-only approach with a VCR for fixed lumbar spinal deformities as well as for severe, rigid scoliosis [11, 15-17].

The purposes of this study were (1) to describe the technique for an all-posterior VCR approach for treating severe pediatric and adult spinal deformity since 2002; and (2) to report our experience along with radiographic and clinical results, perioperative and postoperative morbidity, and complications of this approach. Our hypothesis was that this posterior VCR approach can obviate the need for a circumferential approach in both primary and revision settings for patients with severe spinal deformities.

\section{Materials and Methods}

We retrospectively reviewed 43 pediatric and adult patients with severe spinal deformities who underwent a posterioronly VCR between 2002 and 2006. Although this is the largest series reported on thus far, the numbers and diversity of patients and diagnoses prevented statistical analysis. We included a heterogeneous group of pediatric and adult patients whose common denominators are both a severe and stiff spinal deformity treated with a VCR procedure. Indications for surgery were severe and/or rigid spinal deformity divided into four categories: (1) severe scoliosis (SS, $\mathrm{n}=7$ ); (2) global kyphosis ( $\mathrm{GK}, \mathrm{n}=12$ ); (3) angular kyphosis (AK, $\mathrm{n}=10$ ); and (4) combined kyphoscoliosis $(\mathrm{KS}, \mathrm{n}=14)$. Preoperatively, we documented motor strength on all patients. Flexibility was assessed on sidebending radiographs for scoliosis deformities and hyperextension bolster lateral radiographs for those with a component of kyphosis. These patients were either in good balance or out of balance before their posterior vertebrectomy procedure and would all have undergone a circumferential anterior and posterior procedure instead of their posterior VCR. The minimum followup was 2 months (average, 2 years 2 months; range, 2 months to 4 years 6 months) (Table 1). No patients were lost to followup.

The location of the VCR is always at the apex of the deformity in the coronal and/or sagittal plane. The number of vertebrae resected is based on a combination of the height of the vertebrae, the severity of the deformity, and the overall condition of the spinal cord at the level of the resection. The goal is to do the least amount of resection that affords safe and adequate correction of the deformity. Thus, the majority of the VCRs were one-level, but some two- and three-level resections were performed, especially when decompressing a ventrally stenotic spinal cord. The majority of the procedures (40 of 43 [90\%]) were performed at $\mathrm{L} 1$ or cephalad in the region of the spinal cord. The remaining three procedures were performed in the upper cauda equina region (L2 and/or L3) (Table 2).

Thirty-seven of these procedures were performed in a single stage with the remaining six treated with a two-stage procedure. We believe one should begin the VCR portion within 5 to 6 hours into the surgical procedure. If this is not the case, then typically we will place temporary rods into the screw fixation points and return another day to complete the VCR procedure. The overall goal was to perform the entire procedure in less than a 10- to 12-hour operative time if this is performed in one setting.

The surgical technique involved in a posterior VCR is quite demanding and requires the operating team to be well versed in spinal deformity surgical techniques. In revision patients and even some primary patients, a preoperative three-dimensional computed tomographic scan is helpful to understand posterior vertebral column pathoanatomy before surgery. (Appendix 1, a detailed description of the surgical technique, is available with the online version of CORR.) All patients were rigidly stabilized with segmental pedicle screw instrumentation to allow upright posture immediately after surgery. We routinely monitored the spinal cord during surgery. We obtained standing anteroposterior and lateral radiographs before discharge.

Most patients sat and dangled on the side of the bed on postoperative Day 1 and were out of bed and to a chair by postoperative Day 2. A few pediatric patients having soft bone or those with cervicothoracic constructs were braced for 3 to 4 months after surgery. No adult patient was braced after surgery. The average length of stay was 10 days (range, 6-23 days).

The operating surgeon and/or the spine fellow saw the patients in followup at approximately 2 months, 6 months, and 1,2 , and 5 years postoperatively. The frequency of visits was then decreased to every 3 to 5 years as indicated. We performed clinical evaluations documenting wound healing, posture, spinal balance, gait, and motor strength at each postoperative examination.

At each visit, we obtained anteroposterior and lateral standing radiographs of the entire spine. We measured the curve angles and correction using the Cobb method [5].

\section{Results}

The average radiographic major curve correction was $57^{\circ}$ (69\%) for the scoliosis cases, $45^{\circ}$ (54\%) for the global kyphosis cases, $49^{\circ}(63 \%)$ for the angular kyphosis cases, 


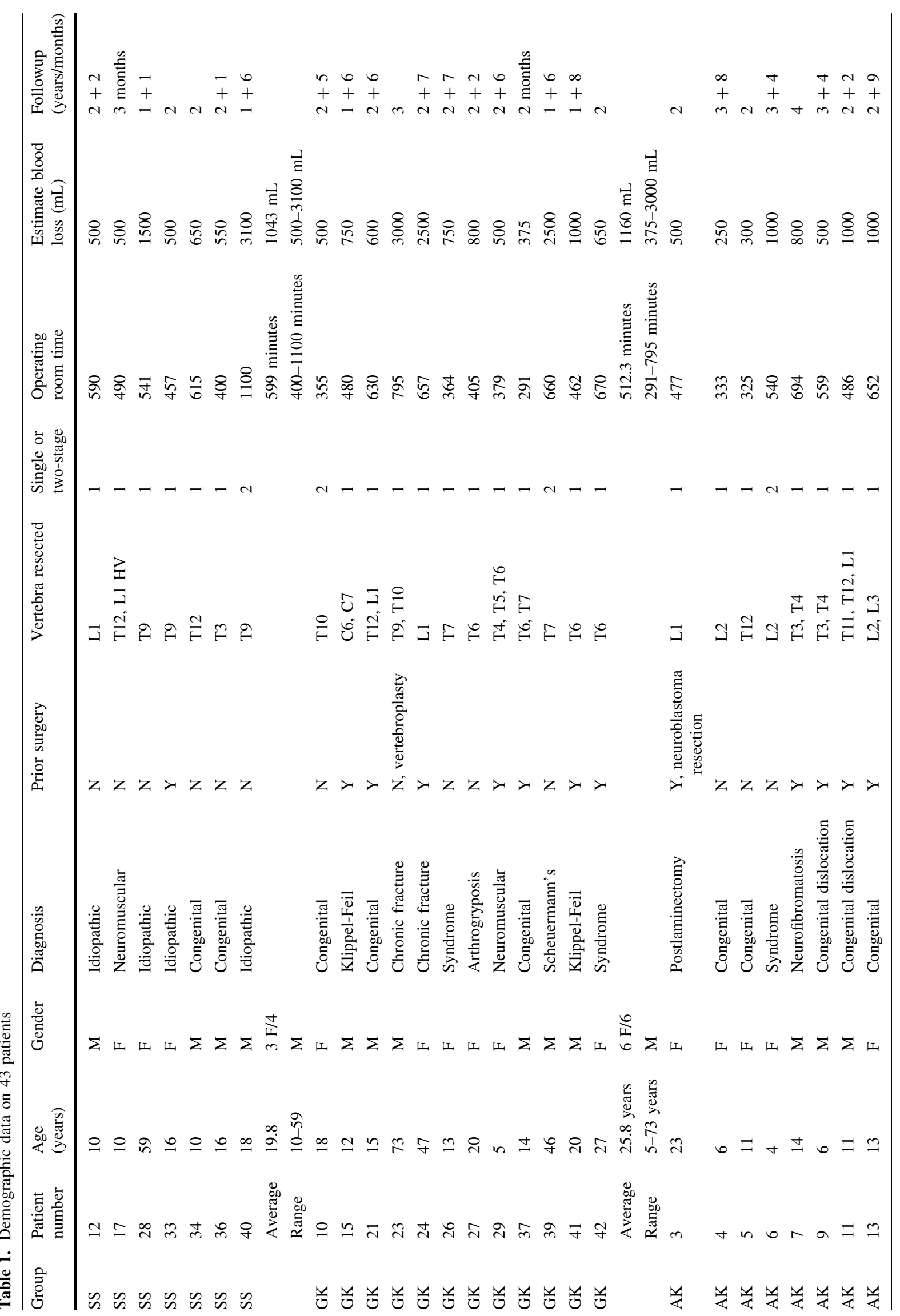




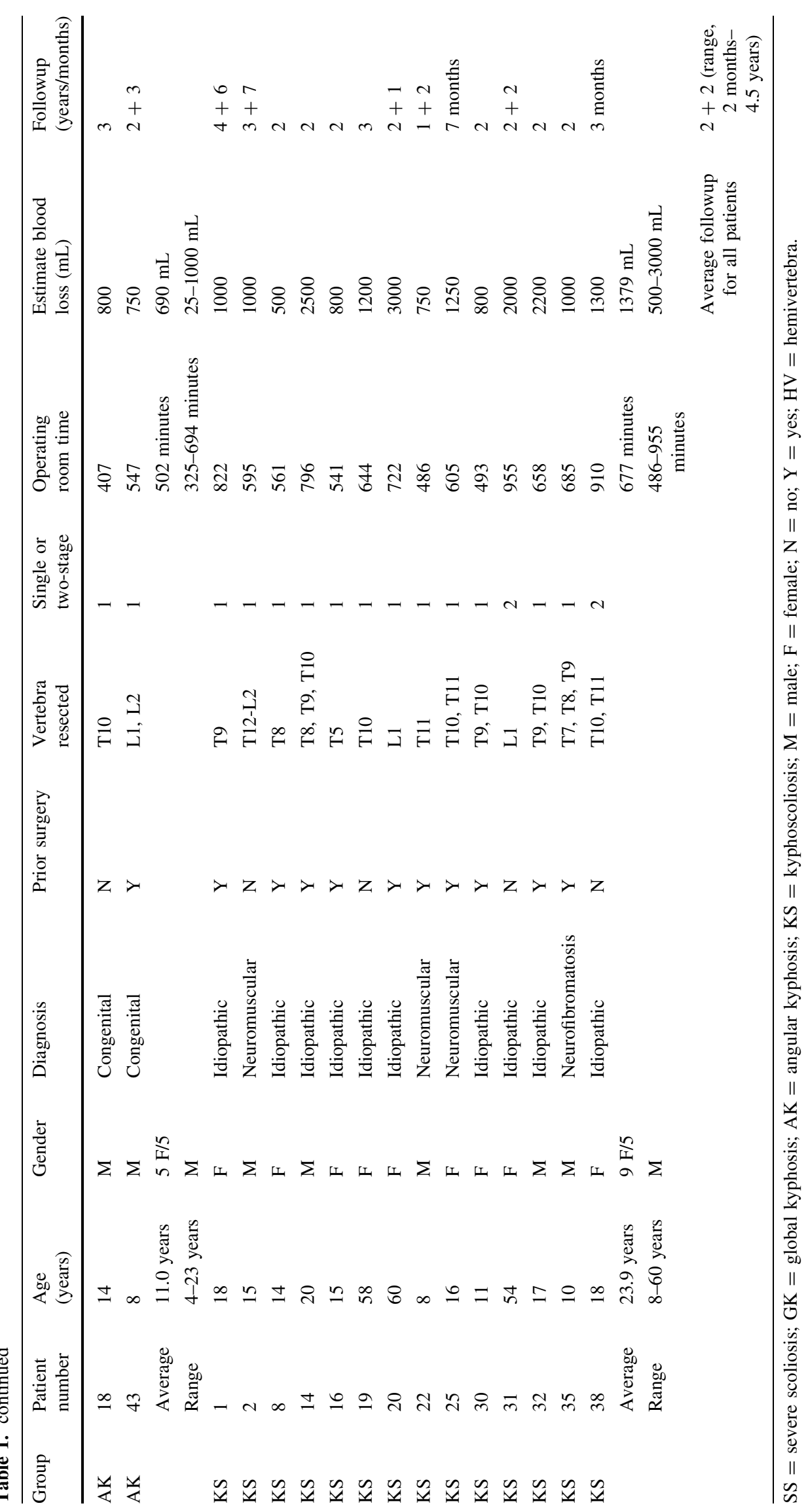


Table 2. Comparison of age, number of levels, and diagnoses of pediatric versus adult cases

\begin{tabular}{lll}
\hline Parameter of comparison & Pediatric $(\mathrm{n}=31)$ & Adult $(\mathrm{n}=12)$ \\
\hline Age (years) & 13 (range, 4-18) & 52 (range, 20-73) \\
1-level VCR & 15 & 10 \\
2-level VCR & 12 & 1 \\
3-level VCR & 4 & 1 \\
Diagnosis & & \\
$\quad$ SS & 6 & 1 \\
$\quad$ GK & 6 & 6 \\
AK & 9 & 1 \\
KS & 10 & 4 \\
\hline
\end{tabular}

$\mathrm{VCR}=$ vertebral column resection; $\mathrm{SS}=$ severe scoliosis; $\mathrm{GK}=$ global kyphosis; $\mathrm{AK}=$ angular kyphosis; $\mathrm{KS}=$ kyphoscoliosis.

and a combined $109^{\circ}(56 \%)$ for the kyphoscoliosis cases (Table 3; Fig. 1).

The average estimated blood loss for all patients was $1103 \mathrm{~mL}$, ranging from 250 to $3100 \mathrm{~mL}$. No patient became coagulopathic intraoperatively, and no patient received platelets or fresh-frozen plasma. The average operative time was 9 hours 37 minutes, ranging from 4 hours 51 minutes to 18 hours 20 minutes for all procedures (Table 1). Twenty patients had pre- and minimum 1-year postoperative Scoliosis Research Society scores with a mean preoperative score of 80 (69\% of the maximum score) and a mean postoperative score of 113 (77\% of the maximum score).

After surgery, all patients were at their baseline $(n=40)$ or showed improved spinal cord function $(\mathrm{n}=3)$, whereas no one worsened. Several patients had changes and/or data loss with spinal cord monitoring: seven patients (18\%) lost intraoperative neurogenic monitoring evoked potentials (NMEP) data during correction with data returning to baseline after prompt surgical intervention. All seven of these patients had some form of preoperative kyphosis (GK, one; AK, two; KS, four). Five of the seven patients had some type of spinal column subluxation occur during the vertebrectomy site closure. In five of the patients, subluxation occurred with actual closure of the vertebrectomy site with the most common impingement being the ventral aspect of the proximal level of the spinal cord. In one patient (GK), NMEP data were lost with closure but returned with reopening the osteotomy site and closure over a cage. In another patient (AK), overshortening of the spinal cord occurred with closure over a small cage. When a larger cage was inserted with compression, the data remained normal. All seven of these patients had NMEP data return to baseline promptly after the surgical correction of subluxation or placement of a larger anterior cage. One patient had loss of unilateral somatosensory evoked potentials (SSEPs) and NMEP data on the convexity of a large kyphoscoliosis. We believed the deficit was most likely the result of inadvertent unilateral spinal cord compression from a cottonoid placed to control profuse epidural bleeding. After removing the cottonoid, the SCM data returned to baseline and a normal wakeup test occurred. A temporary rod was placed, the procedure was aborted, and the patient's wound was closed. The patient awoke with completely normal neurologic function in both lower extremities. She remained neurologically intact and her surgery was completed 1 week later without any sequelae. One patient without any SCM data failed a wakeup test after closure of the vertebrectomy defect. However, function returned after reopening of the defect, placement of an anterior cage, and then recompressing posteriorly.

Postoperative neurologic complications included two patients who had transient nerve root palsies. One patient who underwent a revision L2 and L3 VCR had a unilateral quadriceps deficit that was noted immediately after surgery. The patient was immediately re-explored where the left-sided L2 and L3 nerve roots were identified and further decompression was performed. The deficit resolved spontaneously 6 months after surgery. A second case, a revision T12 and L1 VCR with preoperative 4/5 strength of the lower extremities, had unilateral foot drop that resolved by 2 weeks after surgery. No patient thus far has had revision surgery related to neurologic complications. All patients $(n=4)$ with preoperative spinal cord myelopathy either awoke identical $(n=1)$ or became stronger $(n=3)$ soon after the surgery (Fig. 2). Clinical complications were thoroughly examined and monitored or /treated (Table 4). All patients received perioperative total parenteral nutrition through a central venous line catheter. One patient developed a deep wound infection, which resolved with treatment. No patient has thus far required revision surgery for instrumentation or fusion complications.

\section{Discussion}

For the past several decades, many surgeons have treated severe pediatric and adult spinal deformities with a circumferential approach. However, the recent ability to treat these deformities through an all-posterior VCR has obviated the need for a circumferential approach in primary and revision surgery. To confirm the appropriateness of the VCR approach, the purposes of our study were therefore to (1) describe our experience along with the surgical technique and radiographic and clinical results; (2) define the perioperative and postoperative morbidity; and (3) report complications of this approach. Through this description, we also hoped to describe the pearls, pitfalls, and warning signs associated with this procedure.

Our study had several limitations. First is the heterogeneity in the patient diagnoses and conditions. Second, we 


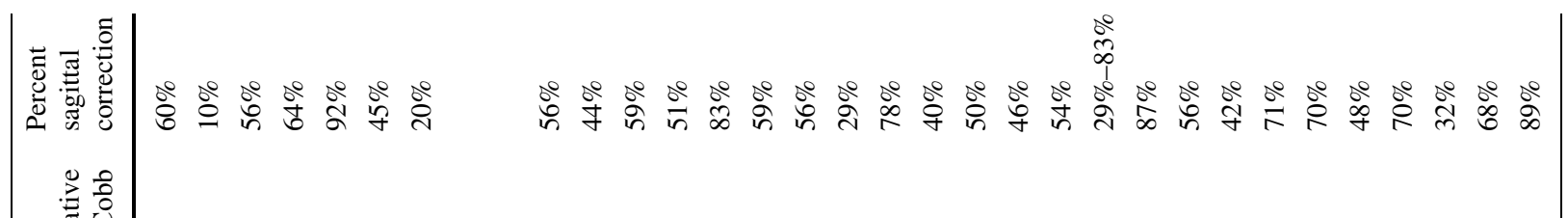

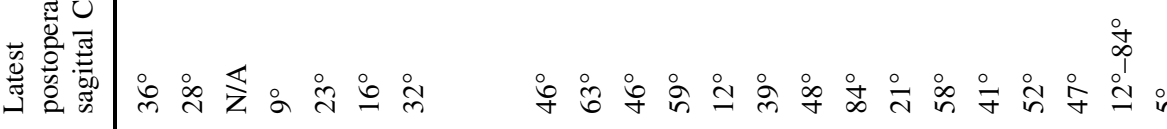 \\ $\circ$

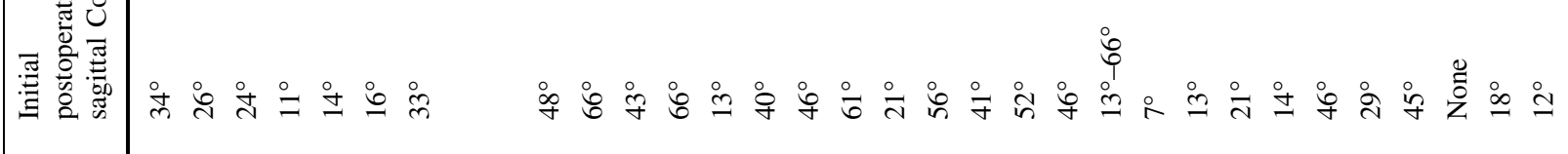

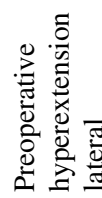 \\ $i \frac{\pi}{z} \frac{\mathbb{z}}{z} \overleftrightarrow{z} \frac{\mathbb{z}}{z}$

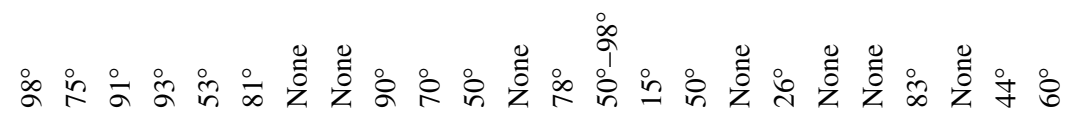

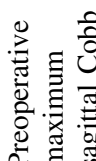

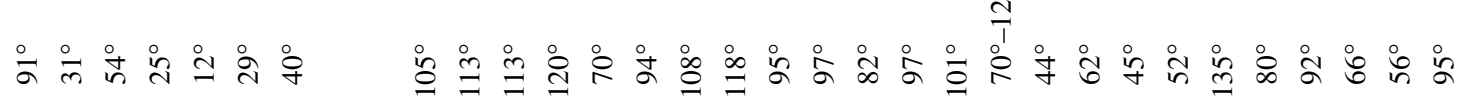

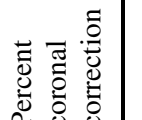

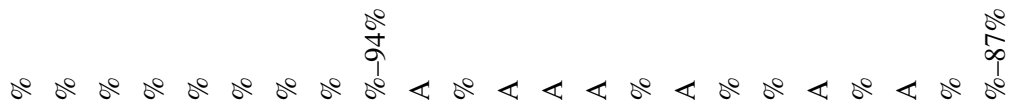

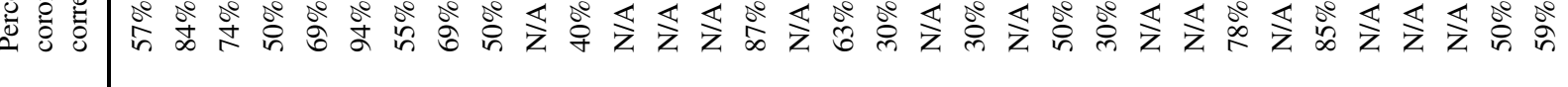 $\sum_{0}^{2} \frac{0}{0}$

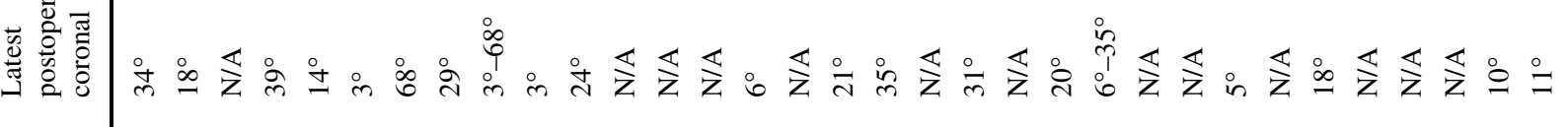 $\stackrel{8}{8}: 0$

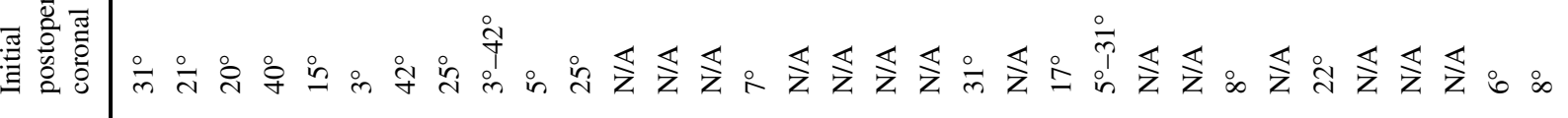

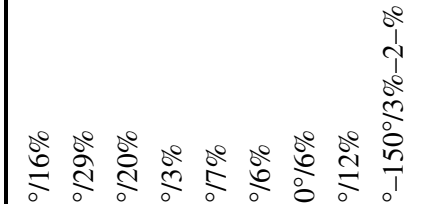

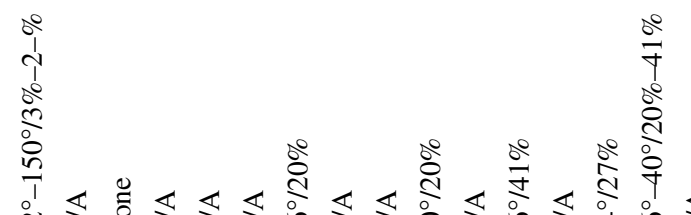

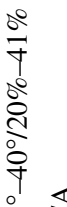

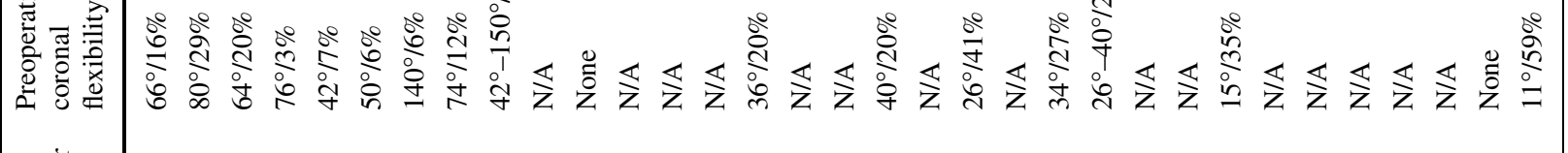

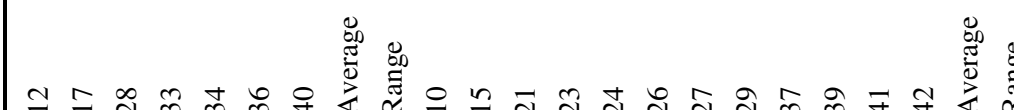

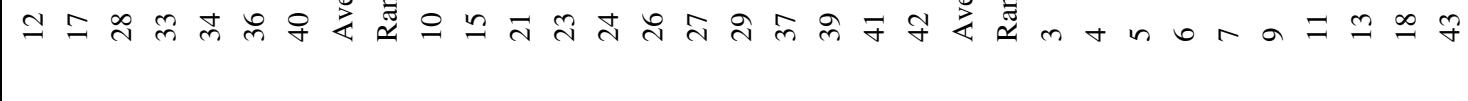

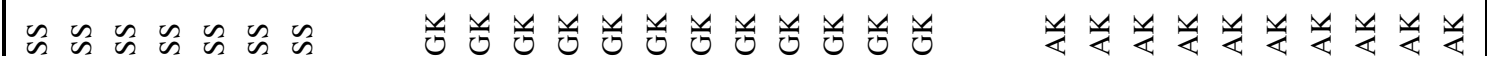




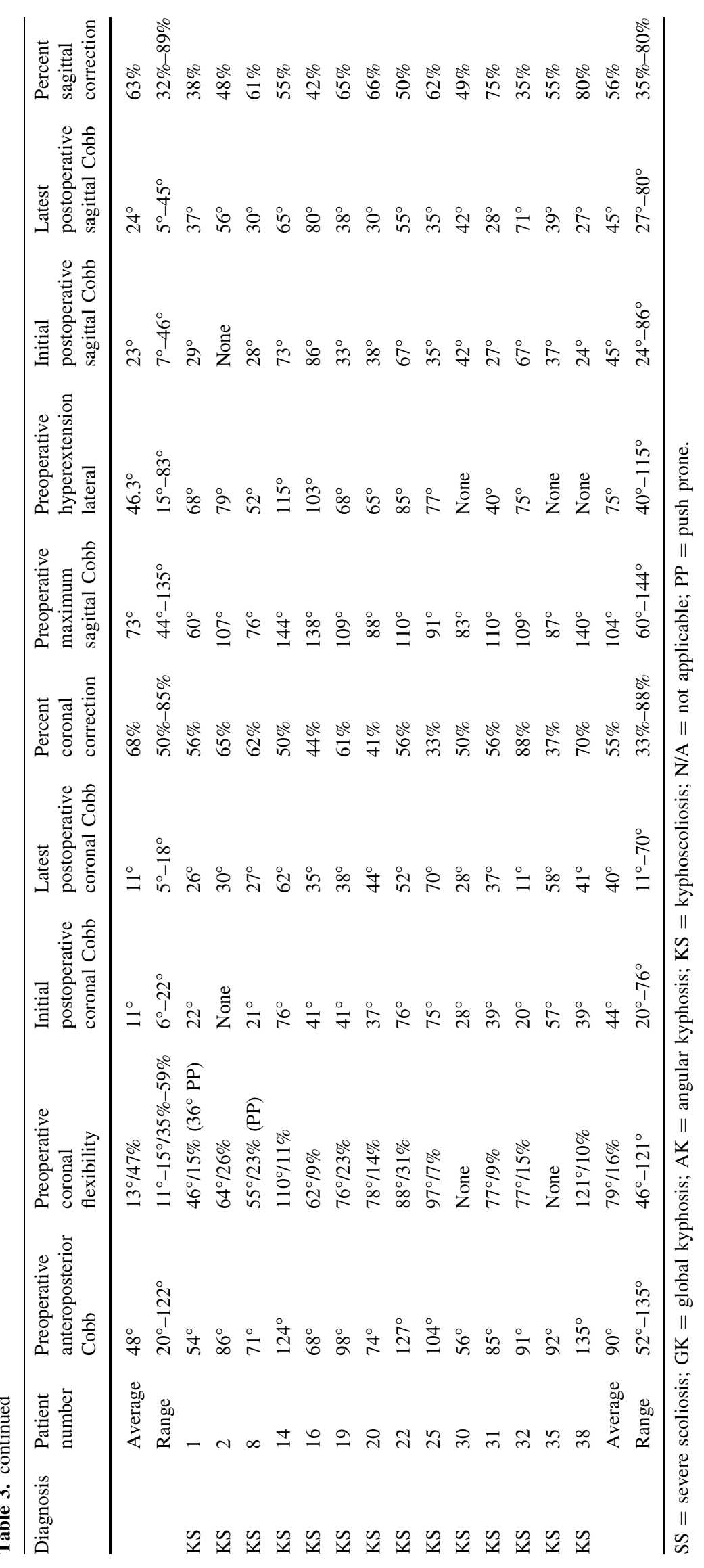


Fig. 1A-D The patient is a $17+8$-yearold girl with severe idiopathic kyphoscoliosis. (A) She had a $135^{\circ}$ coronal plane deformity bending to only $121^{\circ}(11 \%$ flexibility) and a $+140^{\circ}$ kyphosis deformity. Thus, she had $275^{\circ}$ of total kyphoscoliosis deformity. (B) Preoperatively, she was placed in halo-gravity traction for 4 weeks to stretch out her spinal column and to improve her nutritional and respiratory statuses. Her ultimate coronal plane deformity corrected to $102^{\circ}$ and her sagittal plane to $+89^{\circ}$. (C) She underwent a two-stage T10 vertebral column resection with PSF from T2 to L4. Her ultimate coronal plane correction was to $39^{\circ}(72 \%$ correction) with sagittal plane correction to $+24^{\circ}(88 \%)$. (D) Pre- and postoperative clinical photographs show marked correction of her trunk with a concomitant seven-rib thoracoplasty performed to gain full access of her posterior spinal column because of her severe deformity.
A
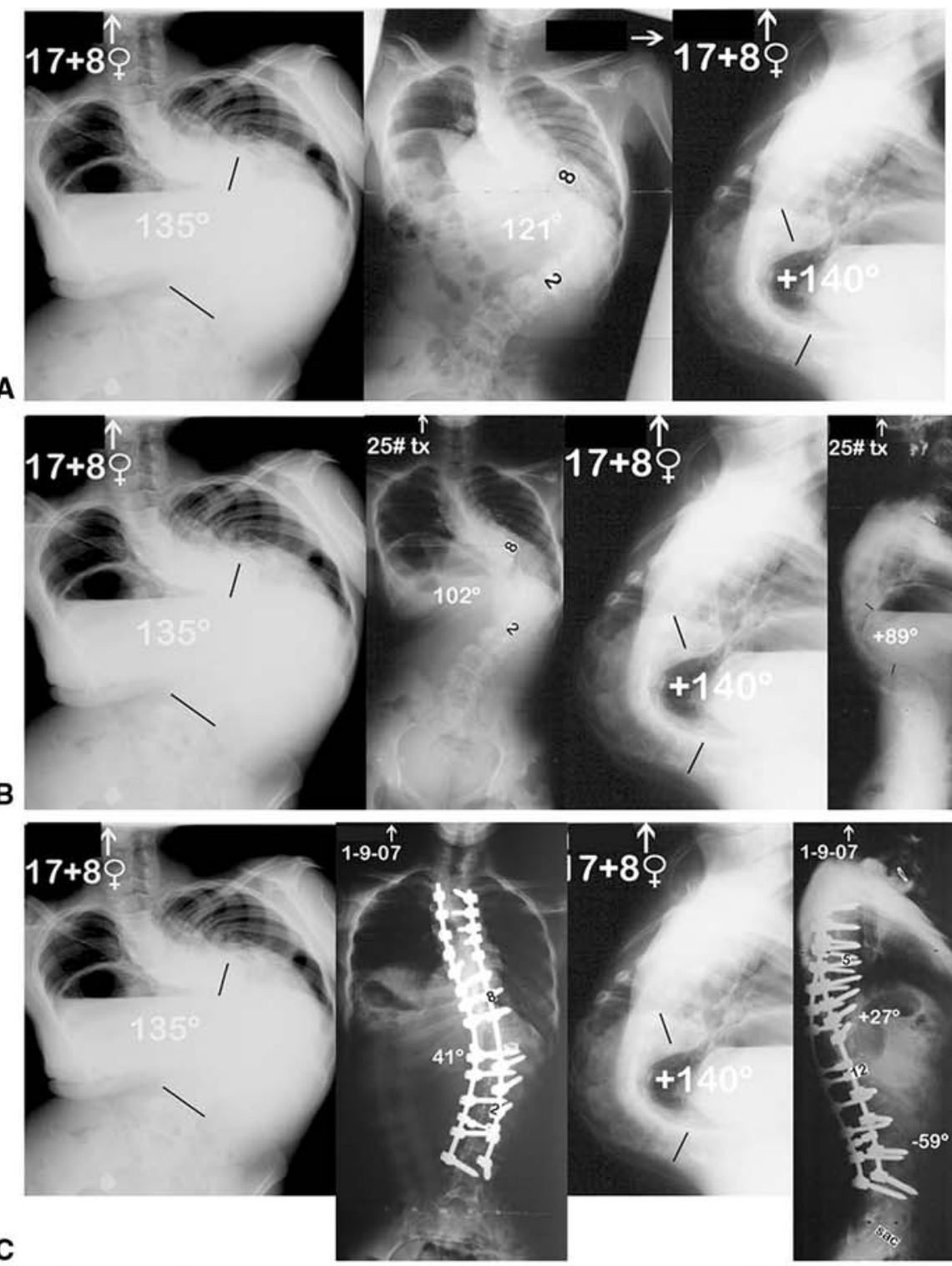

C
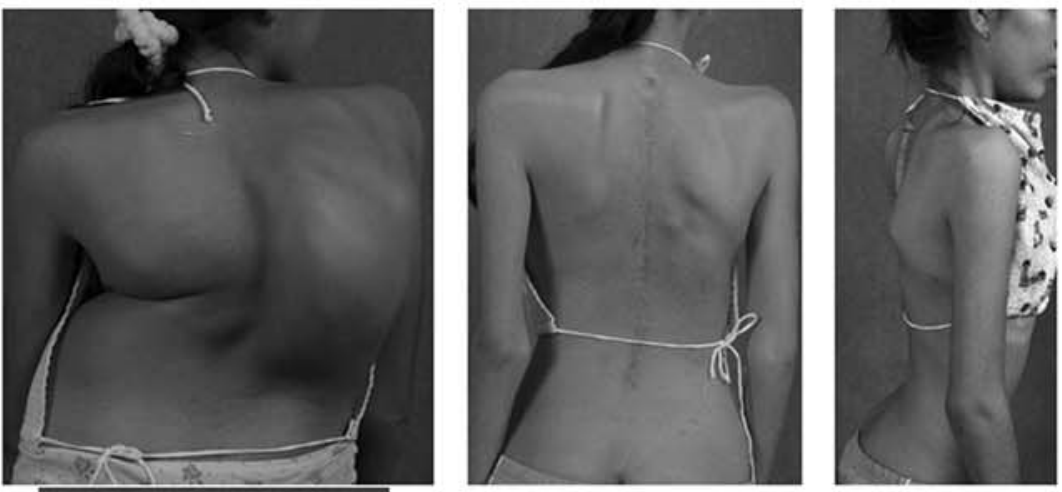

D

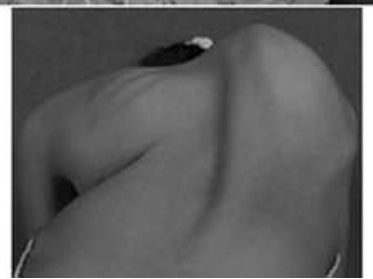


Fig. 2A-E The patient is a $14+7$-year-old boy with neurofibromatosis and eight prior anterior and posterior spinal decompression and fusion attempts with a solid C2-T2 fusion mass. He was myelopathic, could stand but barely walk, with grade 3+/4out of 5 strength in his lower extremities. (A) He had a chin-onchest deformity and $\mathrm{a}+135^{\circ}$ cervicothoracic kyphotic deformity. (B) His preoperative MRI showed a kyphotic T4-5 dislocation with severe compression of the spinal cord at the level. He was initially placed in gradual halo traction, which was locked with his chin out of his chest to allow for fiberoptic intubation with access to his neck if required. (C) He then underwent a posterior $\mathrm{T} 4$ and $\mathrm{T} 5$ vertebral column resection and an occiput to T11 posterior instrumentation and fusion. At 3 years postoperatively, he had a stable construct and alignment with marked correction of his kyphosis to $+41^{\circ}$. (D) One-year postoperative computed tomographic scan shows a solid anterior fusion noted with the use of BMP-2 anteriorly. He already had a wide laminectomy defect posteriorly, which would not allow for any posterior fusion. His neurologic function improved to normal by 6 weeks postoperatively. (E) His 3-year postoperative clinical photos demonstrate the improved head and neck positions.
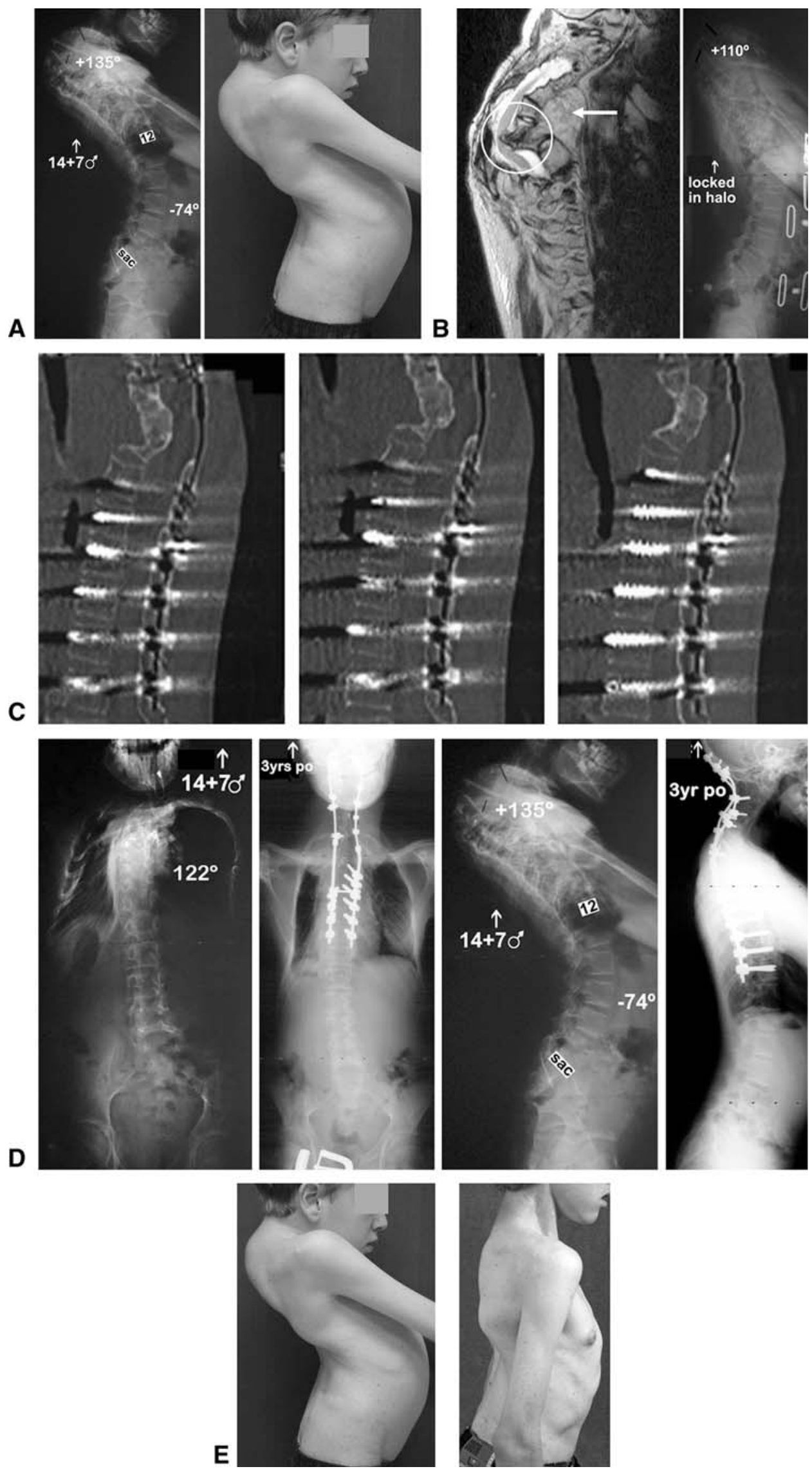
Table 4. Complications of 43 patients

\begin{tabular}{|c|c|c|c|}
\hline Patient number & Diagnosis & Intraoperative & Postoperative \\
\hline 12 & SS & None & None \\
\hline 17 & SS & None & $\begin{array}{l}\text { Diarrhea postoperative Day } 5 ; \\
\quad+\text { for Clostridium difficile; } \mathrm{AB} \text { given }\end{array}$ \\
\hline 28 & SS & None & None \\
\hline 33 & SS & None & None \\
\hline 34 & SS & None & None \\
\hline 36 & SS & None & None \\
\hline 40 & SS & None & None \\
\hline 10 & GK & $\begin{array}{l}\text { NMEP loss; larger cage placed, } \\
\text { subluxation reduced }\end{array}$ & None \\
\hline 15 & GK & None & Respiratory distress; emergent tracheostomy \\
\hline 21 & GK & $\begin{array}{l}\text { No SCM possible; failed wakeup test; } \\
\text { larger cage placed }\end{array}$ & $\begin{array}{l}\text { Bilateral LE subjective "numbness"; subsided } \\
\text { by } 1 \text { month postoperatively; foot drop resolved } \\
2 \text { weeks postoperatively }\end{array}$ \\
\hline 23 & GK & None & Left pulmonary effusion; resolved \\
\hline 24 & GK & None & $\begin{array}{l}2 \text { years postoperative; revision PSF with PSO } \\
\text { for coronal and sagittal imbalance }\end{array}$ \\
\hline 26 & GK & None & $\begin{array}{l}\text { Pleural effusion; started diuretics, resolved; } 2 \text { years } \\
\text { postoperatively; contained DWI; crosslink removal } \\
\text { and AB treatment }\end{array}$ \\
\hline 27 & GK & None & None \\
\hline 29 & GK & None & None \\
\hline 37 & GK & None & None \\
\hline 39 & GK & None & Respiratory failure; reintubation $\times 2$ days \\
\hline 41 & GK & None & None \\
\hline 42 & GK & None & None \\
\hline 3 & $\mathrm{AK}$ & None & None \\
\hline 4 & $\mathrm{AK}$ & & Chronic draining sinus \\
\hline 5 & $\mathrm{AK}$ & None & $\begin{array}{l}\text { DVT right leg; Lovenox therapy (enoxaparin sodium } \\
\text { injection; Sanofi-Aventis Inc, Bridgewater, NJ) }\end{array}$ \\
\hline 6 & $\mathrm{AK}$ & None & None \\
\hline 7 & $\mathrm{AK}$ & None & None \\
\hline 9 & $\mathrm{AK}$ & No SCM & None \\
\hline 11 & $\mathrm{AK}$ & NMEP loss; larger cage placed & None \\
\hline 13 & $\mathrm{AK}$ & $\begin{array}{l}\text { Left quad palsy noted on wakeup test; } \\
\text { left L2-L3 roots re-explored }\end{array}$ & $\begin{array}{l}\text { Decreased strength left quad; normal by } 6 \text { months } \\
\text { postoperatively; revision PSF with PSO below VCR } \\
\text { to improve sagittal alignment at } 2 \text { years postoperatively }\end{array}$ \\
\hline 18 & $\mathrm{AK}$ & None & PJK; no treatment needed, asymptomatic \\
\hline 43 & AK & None & None \\
\hline 1 & KS & None & None \\
\hline 2 & KS & None & None \\
\hline 8 & KS & None & Prolonged ileus \\
\hline 14 & KS & None & None \\
\hline 16 & KS & None & $\begin{array}{l}\text { Tongue swelling; small area } \\
\text { of necrosis; resolved }\end{array}$ \\
\hline 19 & KS & None & Pleural effusion; no CT needed \\
\hline 20 & KS & None & $\begin{array}{l}4 \text { days in ICU secondary } \\
\text { to low blood pressure, } \\
\text { left pleural effusion; resolved; } \\
2 \text { years postoperatively; rod } \\
\text { fracture, asymptomatic }\end{array}$ \\
\hline
\end{tabular}


Table 4. continued

\begin{tabular}{llll}
\hline Patient number & Diagnosis & Intraoperative & Postoperative \\
\hline 22 & KS & None & None \\
25 & KS & NMEP loss; reduced subluxation & Respiratory failure; mechanical vent $\times 4$ days \\
30 & KS & None & None \\
31 & KS & None & None \\
32 & KS & None & None \\
35 & KS & NMEP loss; reduced subluxation & Brachial plexus palsy; resolved by 6 weeks postoperatively \\
38 & KS & NMEP/SSEP loss; failed wakeup test; & Left pleural effusions; bilateral chest tube placement \\
& & right LE procedure aborted, normal & \\
& & final wakeup test; procedure performed & \\
& & 1 week later without problems &
\end{tabular}

SS = severe scoliosis; $\mathrm{GK}=$ global kyphosis; $\mathrm{AK}=$ angular kyphosis; $\mathrm{KS}=$ kyphoscoliosis; $\mathrm{AB}=$ antibiotics; $\mathrm{SCM}=$ spinal cord monitoring; $\quad$ SSEP $=$ somotosensory evoked potentials; $\mathrm{LE}=$ lower extremities; $\mathrm{DVT}=$ diverticulitis; $\mathrm{PSF}=$ posterior spinal fusion; $\mathrm{PSO}=$ pedicle subtraction osteotomy; DWI = deep wound infection; $\mathrm{PJK}=$ proximal junctional kyphosis; $\mathrm{VCR}=$ vertebral column resection; $\mathrm{CT}=$ computed tomography; $\mathrm{ICU}=$ intensive care unit.

had no control group of untreated patients or those with alternative surgical approaches. Both of these limitations relate to the extremely rare and unusual clinical presentation of these types of severe spinal deformity patterns. Third, the followup is short on some of the patients; however, we believe it important to provide complete accounting of all intraoperative and early (1 to 2 months postoperative) complications in these patients and that would have been lost had we excluded patients with short followup.

The use of a vertebrectomy procedure has been around for quite some time with the first description in 1922 by MacLennan who described a posterior apical resection followed by postoperative casting for the treatment of severe scoliosis [13]. After that, several authors recorded their experiences with vertebrectomies, most commonly for the surgical treatment of congenital scoliosis $[3,6-8,10$, 18-20]. In the modern era of spinal deformity surgery, Bradford was the first to describe the use of a circumferential vertebrectomy on patients with severe structural spinal deformities [2]. His report consisted of 13 patients who underwent a one-to seven-level (average, three levels) vertebrectomy. Patients with scoliosis had a preoperative curve averaging $117^{\circ}$, correcting to an average $55^{\circ}$. Patients with kyphosis had a preoperative curve averaging $112^{\circ}$, correcting to an average $56^{\circ}$. The average estimated blood loss was $5800 \mathrm{~mL}$, and the average operative time was 10.5 hours for these combined procedures. Bradford and Tribus later reported 24 patients with rigid coronal decompensation who underwent a circumferential VCR [3]. The average preoperative scoliosis was $103^{\circ}$ corrected by $52 \%$. Importantly, coronal and sagittal imbalances were corrected to an average of $82 \%$ and $87 \%$, respectively. However, there was an average operative time of over 12 hours, an average blood loss of $5500 \mathrm{~mL}$, and 31 overall complications.
Suk et al. [17] first promoted a posterior-only VCR. They believed the total operating time and blood loss was reduced through this one-stage posterior-only procedure. In 2005, Suk et al. reported 16 patients (average age, 29 years) who underwent a posterior VCR having a minimum 2-year followup [15]. Their indication for this procedure was scoliosis of more than $80^{\circ}$ with flexibility less than $25 \%$. There was an average of 1.3 vertebrae removed, 15 performed in the thoracic spine and six performed in the lumbar spine. The mean preoperative scoliosis of $109^{\circ}$ was corrected to $46^{\circ}$ (59\% correction). However, complications were encountered in four patients, including one with complete permanent paralysis. Suk et al. [15] recommended this as an effective alternative for severe rigid scoliosis but cautioned that it was a highly technical procedure and should only be performed by an experienced surgical team. It is important to note, he did not use any form of motor tract monitoring during the surgeries, only SSEP monitoring. Our series of 43 patients undergoing posterior-only VCR for severe pediatric and adult spinal deformity is both complimentary and additive to these prior reports. The severe scoliosis cases had a correction rate of $69 \%, 54 \%$ for the global kyphosis cases, $63 \%$ for the angular kyphosis cases, and $56 \%$ for the combined kyphoscoliosis cases, which is as good as or better than other correction rates reported in the literature by either circumferential or posterior-only vertebrectomy (Table 5).

We identified no spinal cord-related neurologic deficits in any of the patients in this series. We attribute this to several factors, including the routine use of NMEP monitoring in those patients who had available spinal cord monitoring potentials (40 of 43). Seven patients lost NMEP data some time during the surgical procedure, most commonly during the actual spinal shortening and correction. The most common reason for lost NMEP data was spinal 
Table 5. Comparisons to the literature

\begin{tabular}{|c|c|c|c|c|c|c|c|}
\hline Author & $\begin{array}{l}\text { Number } \\
\text { of patients }\end{array}$ & $\begin{array}{l}\text { Number VCR } \\
\text { levels }\end{array}$ & Approach & $\begin{array}{l}\text { Average major } \\
\text { curve preoperatively }\end{array}$ & $\begin{array}{l}\text { Average major } \\
\text { curve correction }\end{array}$ & $\begin{array}{l}\text { Average estimated } \\
\text { blood loss }\end{array}$ & $\begin{array}{l}\text { Average } \\
\text { operative time }\end{array}$ \\
\hline Bradford [2] & 13 & $\begin{array}{l}3 \text { average } \\
\quad \text { (range, 1-7) }\end{array}$ & Ant/Post & 117 & $53 \%$ & 5800 & 10.5 hours \\
\hline $\begin{array}{l}\text { Bradford } \\
\text { and Tribus [3] }\end{array}$ & 24 & $\begin{array}{l}1.3 \text { average } \\
\quad \text { (range, } 1-3)\end{array}$ & Ant/Post & 103 & $52 \%$ & 5500 & $>12$ hours \\
\hline Suk et al. $[15,16]$ & 16 & 1.3 average & Post only & 109 & $59 \%$ & 7034 & 6 hours 11 minutes \\
\hline $\begin{array}{l}\text { Lenke et al. } \\
\text { [Current study] }\end{array}$ & 43 & $\begin{array}{l}1.5 \text { average } \\
\quad(\text { range, } 1-3)\end{array}$ & Post only & 92 & $61 \%$ & 1103 & 9 hours 37 minutes \\
\hline
\end{tabular}

$\mathrm{VCR}=$ vertebral column resection; Ant $=$ anterior; Post $=$ posterior.

subluxation, which can occur before, during, or even after the corrective procedure. The spine is rendered extremely unstable during this posterior reconstruction and thus it is imperative to regain primary stability with a dural sac that is free from compression and not excessively shortened ventrally (especially during kyphotic reconstructions). In three patients (two with and one without available spinal cord monitoring), overshortening of the ventral spinal cord led to the loss of data in one and a failed wake-up test in the other. Restoring appropriate anterior height through a larger anterior cage restored the NMEP data in two and neurologic function in the other. We also strongly believe it is important to maintain normotensive anesthesia during correction and closure of these deformities. We prefer to have the mean arterial pressure at least 75 to $80 \mathrm{mmHg}$ during this time. Occasionally, this will require the adjunctive use of dopamine as a low-dose inotrope and providing blood products as needed. As one might anticipate, the occurrence of NMEP data loss was in patients with a primary or secondary kyphotic malalignment to the spine with the highest risk being the angular kyphosis group.

As evidenced by prior reports, these surgeries have a very high neurologic risk. This is in part the result of the severe nature of the deformity and in part the result of the instability created to correct these deformities with segmental instrumentation [12]. Thus, we believe it imperative to use intraoperative spinal cord monitoring with some form of motor tract monitoring to provide early detection of data loss, which allows for immediate correction of the cause. In our series, we were fortunate to have the NMEP data return quickly with the aid of prompt and precise surgical techniques in the seven cases that lost data out of the 40 cases that had monitoring. Although difficult to prove, it is certainly realistic that our neurologic complication rate would have been much higher without the early detection that is obtainable with the use of multimodality SCM.

The contraindications for this procedure would be (1) surgeon unfamiliarity with this advanced technique; (2) ability to obtain adequate deformity correction with a less invasive approach (eg, posterior column-based osteotomies alone); and (3) inability to obtain spinal cord monitoring data (relative contraindication), which would create an increased neurologic risk during the surgery and require multiple wake-up tests to be performed.

The surgical treatment of severe spinal deformity is challenging. Traditionally, a circumferential approach with anterior releases through discectomies followed by posterior instrumentation and fusion has been the standard of care. A posterior-based VCR is a safe but challenging technique for treating severe primary or revision pediatric and adult spinal deformity. Intraoperative spinal cord monitoring, especially some form of motor tract monitoring, is mandatory to prevent spinal cord-related neurologic complications. This posterior-only approach also allows for dramatic radiographic and clinical correction of these severely deformed patients.

Acknowledgments We thank the many spine fellows at Washington University St Louis who assisted in these complex surgeries and managing the patients postoperatively.

\section{References}

1. Boachie-Adjei O, Bradford DS. Vertebral column resection and arthrodesis for complex spinal deformities. J Spinal Disord. 1991;4:193-202.

2. Bradford DS. Vertebral column resection. Orthop Trans. 1987;11:502.

3. Bradford DS, Tribus CB. Vertebral column resection for the treatment of rigid coronal decompensation. Spine. 1997;22:1590 1599.

4. Cho KJ, Bridwell KH, Lenke LG, Berra A, Baldus C. Comparison of Smith-Petersen versus pedicle subtraction osteotomy for the correction of fixed sagittal imbalance. Spine. 2005;30:20302037.

5. Cobb JR. The American Academy of Orthopedic Surgeons Instructional Course Lectures. Vol 5. Ann Arbor, MI: Edwards; 1948.

6. Dick J, Boachie-Adjei O, Wilson M. One-stage versus two-stage anterior and posterior spinal reconstruction in adults. Comparison of outcomes including nutritional status, complication rates, 
hospital costs, and other factors. Spine (Phila Pa 1976). 1992;17(Suppl):S310-S316.

7. Herbert JJ. Vertebral osteotomy: technique, indications and results. J Bone Joint Surg Am. 1948;30:680-689.

8. Johnson JR, Holt RT. Combined use of anterior and posterior surgery for adult scoliosis. Orthop Clin North Am. 1988;19:361-370.

9. Kim YJ, Lenke LG, Bridwell KH, Cho YS, Riew KD. Free hand pedicle screw placement in the thoracic spine: is it safe? Spine (Phila Pa 1976). 2004;29:333-342; discussion 342.

10. Leatherman KD. Resection of vertebral bodies. J Bone Joint Surg Am. 1969;51:206.

11. Leatherman KD. The management of rigid spinal curves. Clin Orthop Relat Res. 1973;93:215-224.

12. Leatherman KD, Dickson RA. Two-stage corrective surgery for congenital deformities of the spine. J Bone Joint Surg Br. 1979;61:324-328.

13. MacLennan A. Scoliosis. BMJ. 1922;2:864-866.

14. Mangano DT, Tudor IC, Dietzel C. Multicenter Study of Perioperative Ischemia Research Group. Ischemia Research and
Education Foundation. The risk associated with aprotinin in cardiac surgery. $N$ Engl J Med. 2006;354:353-365.

15. Suk SI, Chung ER, Kim JH, Kim SS, Lee JS, Choi WK. Posterior vertebral column resection for severe rigid scoliosis. Spine. 2005;30:1682-1687.

16. Suk SI, Chung ER, Lee SM, Lee JH, Kim SS, Kim JH. Posterior vertebral column resection in fixed lumbosacral deformity. Spine. 2005;30:E703-E710.

17. Suk SI, Kim JH, Kim WJ, Lee SM, Chung ER, Nah KH. Posterior vertebral column resection for severe spinal deformity. Spine. 2002;27:2374-2382.

18. Thomasen E. Vertebral osteotomy for correction of kyphosis in ankylosing spondylitis. Clin Orthop Relat Res. 1985;194:142152.

19. Tokunaga M, Minami S, Kitahara H, Isobe K, Nakata Y, Moriya H. Vertebral decancellation for severe scoliosis. Spine. 2000;25:469-474.

20. Wiles P. Resection of dorsal vertebrae in congenital scoliosis. J Bone Joint Surg Am. 1951;33:151-154. 